\title{
Eritema indurado de Bazin
}

\section{Bazin's indurated erythema}

\author{
Karina Nataly Ordóñez, Alan David Sepúlveda, \\ Ángelo Geovanni Arzuaga, Abraham Enrique Katime, \\ Esperanza Meléndez • Barranquilla (Colombia)
}

\section{Resumen}

Presentamos el caso de una paciente de sexo femenino procedente de la ciudad de Santa Marta (Colombia), con abscesos cutáneos recurrentes de larga evolución, localizados en extremidades, tronco y glúteos, prueba de tuberculina positiva, cultivos y PCR para Mycobacterias negativos, se obtuvo muestra de biopsia y patología que mostró hipodermitis septal y lobulillar con compromiso de lobulillos adiposos e infiltrado linfohistiocitario que insinuó la formación de granuloma, con lo cual se consideró eritema indurado de Bazin, iniciándose terapia antifímica con isoniacida, rifampicina, pirazinamida y etambutol, teniendo como resultado resolución de las lesiones.

Palabras clave: Bazin, tuberculosis, tubercúlides, Mycobacterias, antifimica.

\begin{abstract}
The case of a female patient from the city of Santa Marta (Colombia) with recurrent skin abscesses of long evolution located in extremities, trunk and buttocks, positive tuberculin test and cultures and PCR for negative Mycobacteria is presented. Biopsy sample was obtained and pathology showed septal and lobular hypodermitis with compromise of adipose lobules and lymphohistiocytic infiltrate that suggested the formation of granuloma, which was considered Bazin's Indurated Erythema. Antifungal therapy with isoniazid, rifampicin, pyrazinamide and ethambutol was initiated, resulting in resolution of the injuries.
\end{abstract}

Key words: Bazin, tuberculosis, tuberculides, Mycobacteria, antimicrobial.
Dres. Karina Nataly Ordóñez García, Alan David Sepúlveda Molina, Ángelo Geovanni Arzuaga Hernández: Residentes de Medicina Interna, Universidad Metropolitana Barranquilla; Dr. Abraham Enrique Katime Zúñiga; Internista Infectólogo. Profesor Asociado Universidad Metropolitana. Barranquilla; Dra. Esperanza Meléndez Ramírez: Dermatóloga. Barranquilla (Colombia).

Correspondencia. Dr. Abraham Katime Zúñiga. Barranquilla (Colombia)

E-mail: katime@dr.com

\section{Introducción}

El eritema indurado de Bazin (EIB) es un tipo de tuberculosis cutánea denominada tubercúlides por ser una reacción de hipersensibilidad al Mycobacterium tuberculosis pero con estudios microbiológicos negativos; se notifica con una tasa de incidencia del $1 \%$ entre todos los otros tipos de tuberculosis (1), se considera por esta razón que el siguiente caso es de importancia clínica por su baja incidencia; además del tiempo que requirió para llegar a su diagnóstico el cual fue de seis años y se resalta la importancia de sospechar la enfermedad en pacientes con abscesos cutáneos recurrentes con estudios microbiológicos y moleculares negativos de forma seriada.

\section{Caso Clínico}

Presentamos el caso de una mujer de 55 años, ama de casa, procedente de la ciudad de Santa Marta (Colombia), que consulta por un cuadro clínico de seis años de evolución consistente en la presencia de abscesos cutáneos recurrentes, localizados en extremidades, glúteos y tronco (Figura 1), de características inicialmente en forma de nódulos y que pos- teriormente progresaban a abscesos dolorosos que dejaban cicatrices hiperpigmentadas y con piel engrosada en el sitio de la lesión, se presentaron de aparición insidiosa, que se manifestaron posterior al inicio de inmunoterapia para tratamiento de rinitis alérgica, en el transcurso de su presentación fue valorada por varios especialistas que indicaron diversos tratamientos sin respuesta clínica adecuada.

Debido a la clínica y tiempo de evolución de las lesiones se realizan pruebas adicionales a las anteriormente practicadas en la paciente, entre las que se encontraban ANAS (anticuerpos antinucleares), C3, C4 (complemento), ELISA para virus de inmunodeficiencia humana, baciloscopia en heces, orina y esputo, prueba de $\mathrm{KOH}$, serología para sífilis, todos las anteriores negativas; con cultivo de la secreción de los abscesos en los diferentes años inicialmente en 2012 y 2013 positivos para $S$. aureus, A. baumannii y E coli Blee a los cuales recibe manejo antibiótico sin mejoría clínica y recurrencia de los abscesos, posteriormente se realiza prueba de tuberculina en el año 2017, la cual se torna positiva bajo efecto booster con $12 \mathrm{~mm}$. 


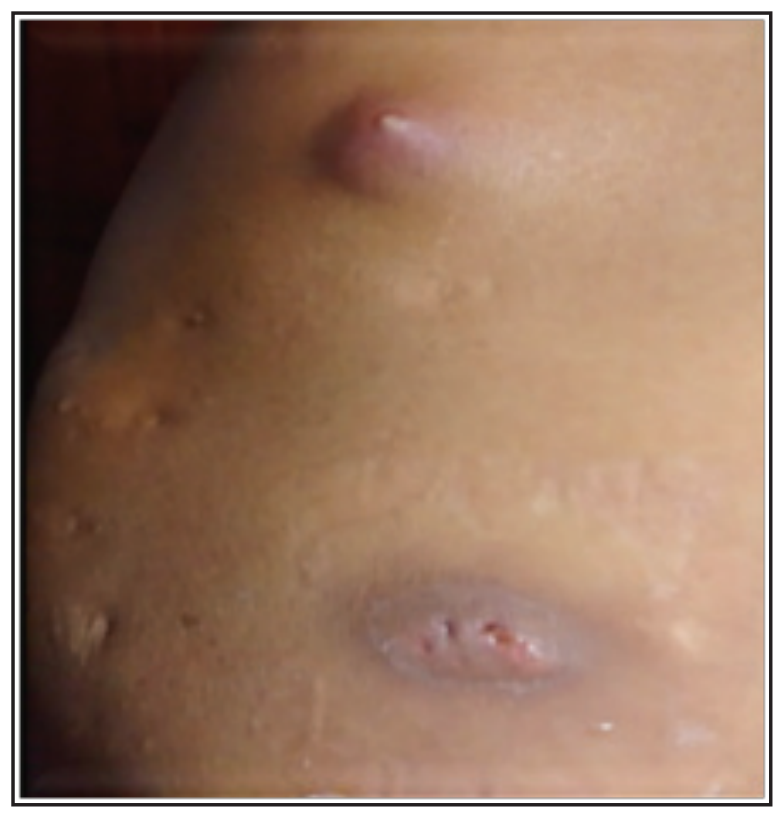

Figura 1a. Lesiones en brazo tipo abscesos, y cicatrices hiperpigmentadas.

Se realiza biopsia que confirma el diagnóstico; reportando hipodermitis con compromiso de lobulillos adiposos e infiltrado linfohistiocitario, que insinúa la formación de granulomas, el cual indica eritema indurado de Bazin.

Se inició tratamiento antifímico con isoniazida, rifampicina pirazinamida, etambutol durante dos meses, y segunda fase con isoniacida y rifampicina hasta completar seis meses, con lo cual se observa mejoría marcada desde el primer mes de tratamiento evidenciándose resolución progresiva de las lesiones (Figura 2), quedando únicamente cicatrices atróficas retráctiles hiperpigmentadas residuales.

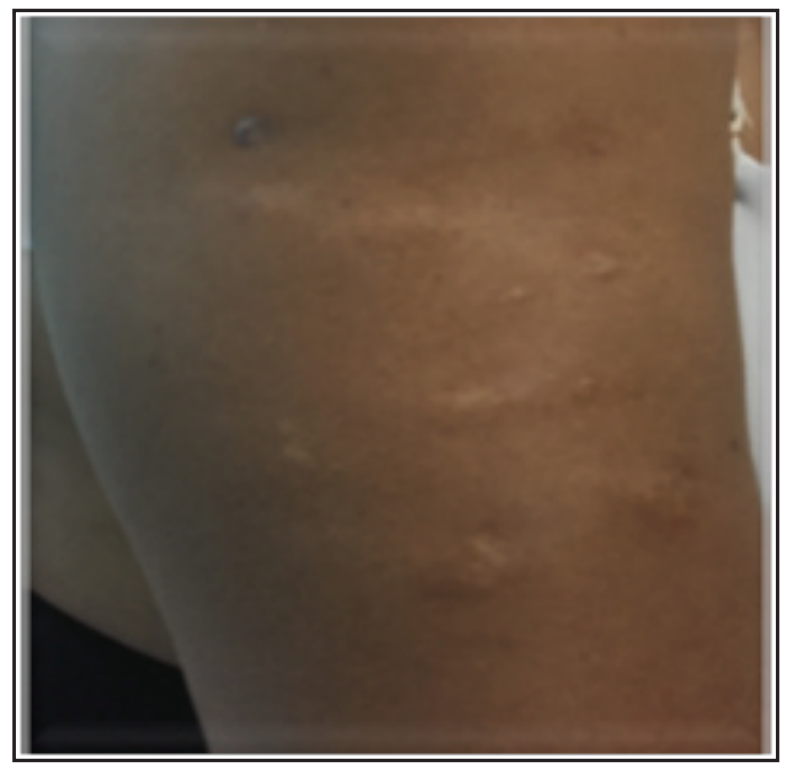

Figura 2a. Lesiones en brazo tipo cicatrices retráctiles hiperpigmentadas.

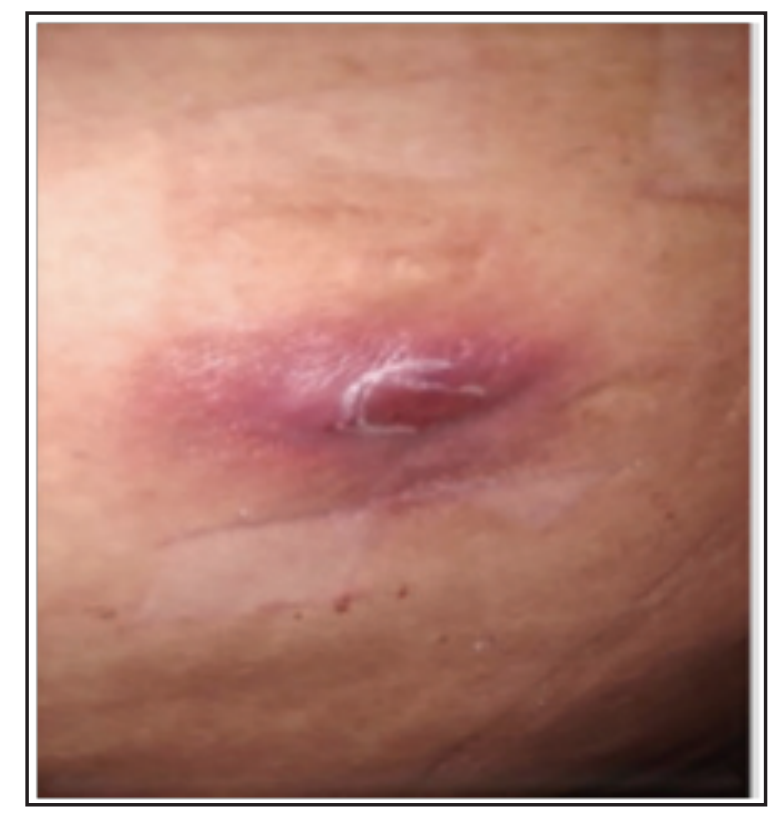

Figura 1b. Absceso localizado en glúteo.

\section{Discusión}

El eritema indurado de Bazin (EIB) también llamado tuberculosis nodular profunda; eritema indurado (Bazin 1885, Colcot-Fox 1893); eritema indurado ulcerado tipo Hutchinson, tuberculosis o tubercúlide indurativa $(2,3)$, es una erupción crónica, nodular, que por lo general se produce en extremidades de las mujeres jóvenes.

EIB ha sido considerada como una manifestación de la hipersensibilidad a Mycobacterium tuberculosis con cultivo negativo (es decir, un tipo de tubercúlide) $(4,5)$. Este trastorno se considera una paniculitis lobulillar inflamatoria

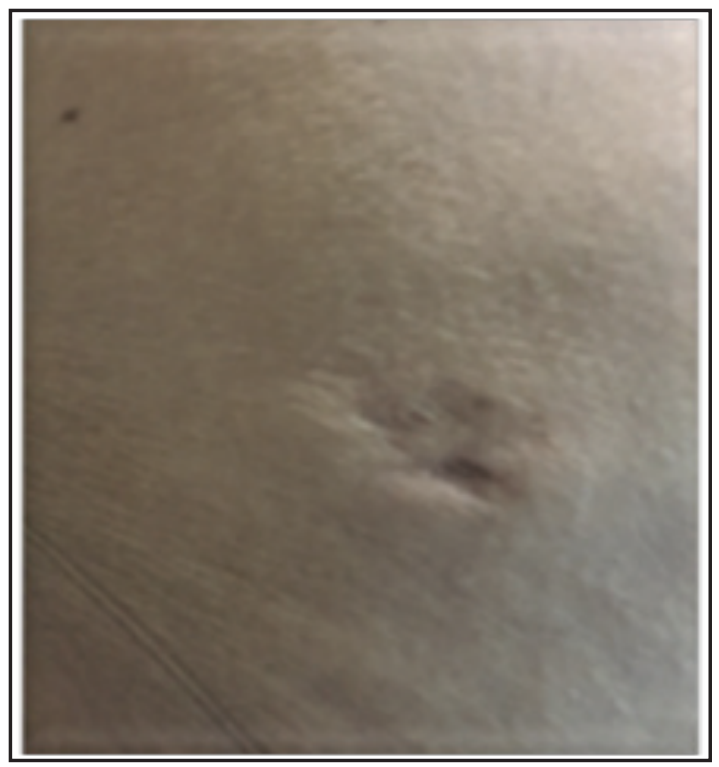

Figura 2b. Cicatriz retráctil en glúteo. 
reactiva, asociada con vasculitis pudiendo afectar vasos sanguíneos de diversos calibres, incluidas las vénulas (6).

Las tubercúlides, concepto introducido por Darier en 1896, las cuales representarían una reacción de hipersensibilidad celular, mediada por células $\mathrm{T}$ en contra de los fragmentos antigénicos de los bacilos que se han depositado por vía hematógena en la piel desde focos tuberculosos internos, cuya ubicación muchas veces no se identifica, para el caso se practicaron estudios de extensión en búsqueda de foco tuberculoso sin poder demostrar ninguno.

Las tubercúlides son entonces reacciones inmunológicas cutáneas desencadenadas por una infección de Mycobacterium tuberculosis en otros lugares. Las tres manifestaciones de los tubercúlides son: liquen escrofuloso, tubercúlides papulonecrótica, y EIB siendo esta última la más común (7).

Realizamos entonces diagnóstico diferencial de estas tres formas de presentación para la paciente, determinando que por las características clínicas de nódulos y abscesos y no de pápulas ni de máculas se trataba de un tipo de eritema indurado considerándose que las lesiones no correspondían con las dos primeras.

Generalmente ocurren en pacientes con un grado moderado a alto de inmunidad para tuberculosis, manifestado por prueba de Mantoux positiva (7), en este caso recordemos que la paciente tiene antecedente de un tipo de hipersensibilidad a ácaros causándole rinitis alérgica crónica, lo cual nos determina un estado inmunológico alterado de base.

El diagnóstico suele hacerse con base a sospecha clínica, una prueba de tuberculina y la patología, y debido a que el bacilo es usualmente negativo en los cultivos de las lesiones en piel se realiza prueba cutánea de la tuberculina (prueba de Mantoux), la cual nos detecta la respuesta inmune cutánea al antígeno derivado de M. tuberculosis (PPD), así como la histopatología en donde podemos encontrar granulomas que contengan células gigantes de Langerhans, áreas focales de necrosis de grasa en la dermis e hipodermis (8).

Por otro lado en búsqueda de otras ayudas diagnósticas, se encontró un reciente estudio de 13 casos de tuberculosis cutánea en Francia, en donde seis de éstos fueron secundarios a EIB, a los cuales se valora las diferentes ayudas diagnósticas utilizadas como: histopatología, cultivo, PCR (reacción en cadena de la polimerasa), baciloscopia, test de interferón y toracodensitometría, encontrando que la tinción con Ziehl en secciones histológicas siempre fue negativo cuando se realizó $(n=4)$, la PCR para el complejo Mycobacterium tuberculosis en la muestra cutánea fue negativa en los dos casos en que se realizó, el test de interferón gamma (Quantiféron ${ }^{\circledR}$ ) fue positivo en cinco casos de seis, la PPD fue positiva en los cuatro casos (9); con lo anteriormente descrito podríamos decir que adicional a la PPD y la histopatología, el test de interferón podría ser una alternativa a la hora del diagnóstico en EIB.

Respecto al tratamiento del EIB éste no difiere de la terapia antituberculosa convencional con isoniacida, rifampicina, pirazinamida y etambutol (10) en la que se evidencia una muy buena respuesta al inicio de la terapia, de otra parte no se recomienda la monoterapia con isoniacida por riesgo de resistencia (11).

\section{Conflicto de intereses}

Este caso ninguno de los autores presenta conflicto de interés.

\section{Referencias}

1. Galenos Yayinevi, Turk J. Endocrinol Metab 2015;19: 130-132

2. Gavelán ET, Sánchez Saldaña L, Sáenz Anduaga E, et. al. Eritema indurado de Bazin. Dermatol. Perú. V.16 N², Lima, Mayo/ Agosto 2006.

3. Rodríguez O. Tuberculosis cutánea. Rev. Fac. Med. UNAM Vol.46 No.4 Julio/ Agosto, 2003.

4. Semergen. 2011; Volume 37 corte 5: pág. 255-257.

5. Requena L, Sánchez, Yus E. Panniculitis. Part II. Mostly lobular panniculitis. $J$. Am Acad. Dermatol 2001; 45: 325-61.

6. Camilleri MJ. Paniculitis. Enfermedades del tejido subcutáneo. Sección 14 Cap 109 (1175-1185). Freedber I, Eisen A, Wolff K; Austen K, Goldsmith L, Katz S, Fitzpatrick. Dermat Med Gen. 8va edición. Editorial Medica Panamericana, Buenos Aires, 2005. 7. 2016 Euro Acad Dermat Vener.

7. XU, LI, MA. 2017. Mycobacterium tuberculosis found at both skin lesions and Mantoux testing site in a patient with erythema induratum of bazin, J Derma 2017; $1-3$.

8. Bilan $\mathbf{P}$, et. Al. Tuberculose cutanée et érythème induré de Bazin: étude rétrospective de 13 cas. Ann Dermatol Venereol (2015), Disponible en: http://dx.doi. org/10.1016/j.annder.2015.01.015

9. Inter J Infec Disea 2015, two cases of erythema induratum of Bazin - a rare cutaneous, Disponible en: http://www.ijidonline.com/article/S1201-9712 (15)00197-6/ pdf

10. Rev. Inst. Med. Trop. Sao Paulo 2016; 58:49, cutaneous tuberculosis: a 26-year retrospective study in an endemic area of tuberculosis, vitória, espírito santo, brazil, Disponible en: http://dx.doi.org/10.1590/S1678-9946201658049 